\title{
Effect of boron-containing aggregates on setting and hardening of Portland cement mortars
}

\author{
Aneta Antolik ${ }^{1, *}$, Michat A. Glinicki ${ }^{1}$, and Marek Gawlicki ${ }^{2}$ \\ ${ }^{1}$ Institute of Fundamental Technological Research, Polish Academy of Sciences, Pawińskiego 5B, 02- \\ 106 Warsaw, Poland \\ ${ }^{2}$ Institute of Ceramics and Building Materials, Department of Process and Environmental \\ Engineering, Oświęcimska 21, 45-641 Opole, Poland
}

\begin{abstract}
Multicomponent cement-based composites are known as versatile structural materials for enhanced radiation shielding. The use of selected elements, like boron, cadmium, or rare earth elements, provides an increased neutron shielding capacity. Because of profusion, reasonable costs and large cross-section for neutron capture, boron containing minerals are suggested as aggregates for radiation shielding concrete. Despite many advantages, boron additives may act as cement setting retarders. Uncontrolled setting and hardening is not acceptable in radiation shielding concrete technology. In this work we present results from isothermal calorimetry measurements on cement mortars with boron-containing aggregates. Four types of boron aggregates were used in the studies: colemanite, ulexite, borax and boron carbide. Based on calorimetric curves, the beginning of setting time was determined. Additionally early mortar strength was investigated and linear relationship between the heat generated in the isothermal calorimeter and the early compressive strength has been observed. The use of isothermal calorimetry allowed us to estimate the limits for the content of boron compounds to be used cement mortar.
\end{abstract}

\section{Introduction}

Due to the continuous development of nuclear power and the use of neutron radiation, new solutions for shielding are needed. Radiological protection for personnel and environment requires capturing of highly penetrating neutron radiation. Particular elements, like hydrogen, boron, cadmium, or gadolinium, are known to exhibit outstanding neutron shielding capacity [1-3]. Such elements, preferably in a form of abundant minerals, could be used as fillers or aggregates in radiation shielding concrete $[4,5]$. Because of availability, reasonable costs and large cross-section for neutron capture, boron containing minerals are suggested [6] as beneficial aggregates for radiation shielding concrete.

Boron has a lot of advantages in radiological protection, e.g. high thermal neutron absorption cross section, does not emit highly penetrating gamma radiation. Boron naturally occurs as isotopes ${ }^{10} \mathrm{~B}(20 \%)$ and ${ }^{11} \mathrm{~B}(80 \%)$, the first of them is more important in the shielding. ${ }^{10} \mathrm{~B}$ due to its thermal neutron high absorption capacity results in

\footnotetext{
*Corresponding author: aantolik@ippt.pan.pl
} 
the emmission of easily absorbed weak gamma radiation. The cost of boron-containing minerals is relatively low. However boron compounds are damaged by the absorption of neutrons $\left({ }_{5}^{10} B+{ }_{0}^{1} n \rightarrow{ }_{3}^{7} L i+{ }_{2}^{4} \mathrm{He}\right)$. Moreover, boron compounds are expected to interfere with the setting of Portland cement $[7,8]$.

The objective of this investigation is to study the effects of various boron-bearing compounds on cement setting and hardening in order to evaluate the limits for possible use in radiation shielding cement mortars.

\section{Materials and laboratory test methods}

\subsection{Materials}

Four types of boron-containing aggregates with varied content of boron were tested: colemanite $(0.5-2 \mathrm{~mm}, \mathrm{~B}=15.78 \mathrm{wt} \%)$, ulexite $(0.5-2 \mathrm{~mm}, \mathrm{~B}=13.34 \mathrm{wt} \%)$, sodium tetraborate pentahydrate (borax, $<1.6 \mathrm{~mm}, \mathrm{~B}=14.85 \mathrm{wt} \%$ ) and boron carbide $(90-125 \mu \mathrm{m}$, $94 \%$ of purity, $\mathrm{B}=73.56 \mathrm{wt} \%$ ).

Boron-containing aggregate was used as a partial replacement for quartz sand in Portland cement mortar (CEM I 42.5 R). The boron aggregate content was selected in such a way as to obtain the required amount of boron in relation to the cement mass. Mortar samples were prepared with constant water to cement ratio $\mathrm{w} / \mathrm{c}=0.5$ and aggregate to cement ratio $\mathrm{a} / \mathrm{c}=$ 0.75 .

\subsection{Testing methods}

Isothermal calorimetry

For the determination of rate of heat generation and total heat generated during cement hydration process an isothermal calorimetry method was used. The benefits and limitations of calorimetric methods are known from numerous studies, e.g. $[9,10]$. Tests were carried out on Calmetrix I-Cal $2000 \mathrm{HPC}$ isothermal calorimeter $\left(23^{\circ} \mathrm{C}, 72 \mathrm{~h}\right)$. On Fig. 1 the calorimetric measurement stand has been presented. Mortar samples are placed in channels, where the difference between rate of heat generated by the mortar and the reference sample is measured. As a reference sample, material in which heat is no generated is chosen (in this case aluminium samples).
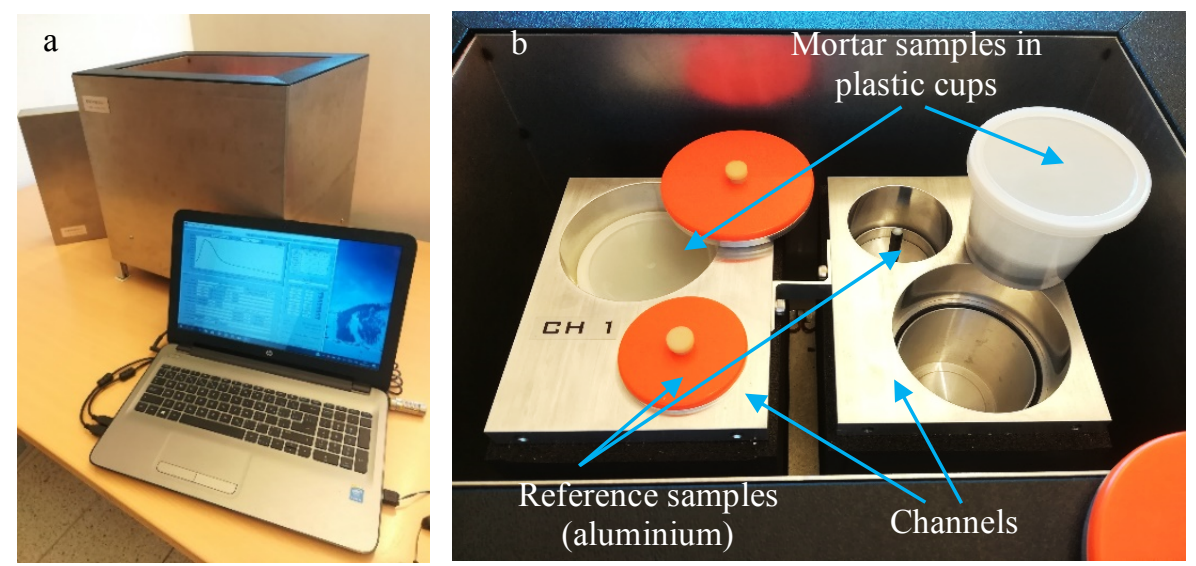

Fig 1. a) Isothermal calorimeter Calmetrix I-Cal2000 HPC, b) interior of the calorimeter chamber. 
Compressive strength tests

According to the standard EN 196-1, compressive strength tests were carried out. Tests were performed on the $40 \times 40 \times 160$ prisms after $72 \mathrm{~h}$ and after 28 days of hardening. Three tests were made for each mortar.

\section{Results and discussion}

Results from isothermal calorimeter tests are shown on Fig. 2 a-d. On graphs a-c the rate of heat generation for four different boron-containing aggregates is presented with the same percentage content of boron $(2.5,5.0,10.0 \mathrm{wt} \%$ of $\mathrm{B})$ in relation to the cement mass.
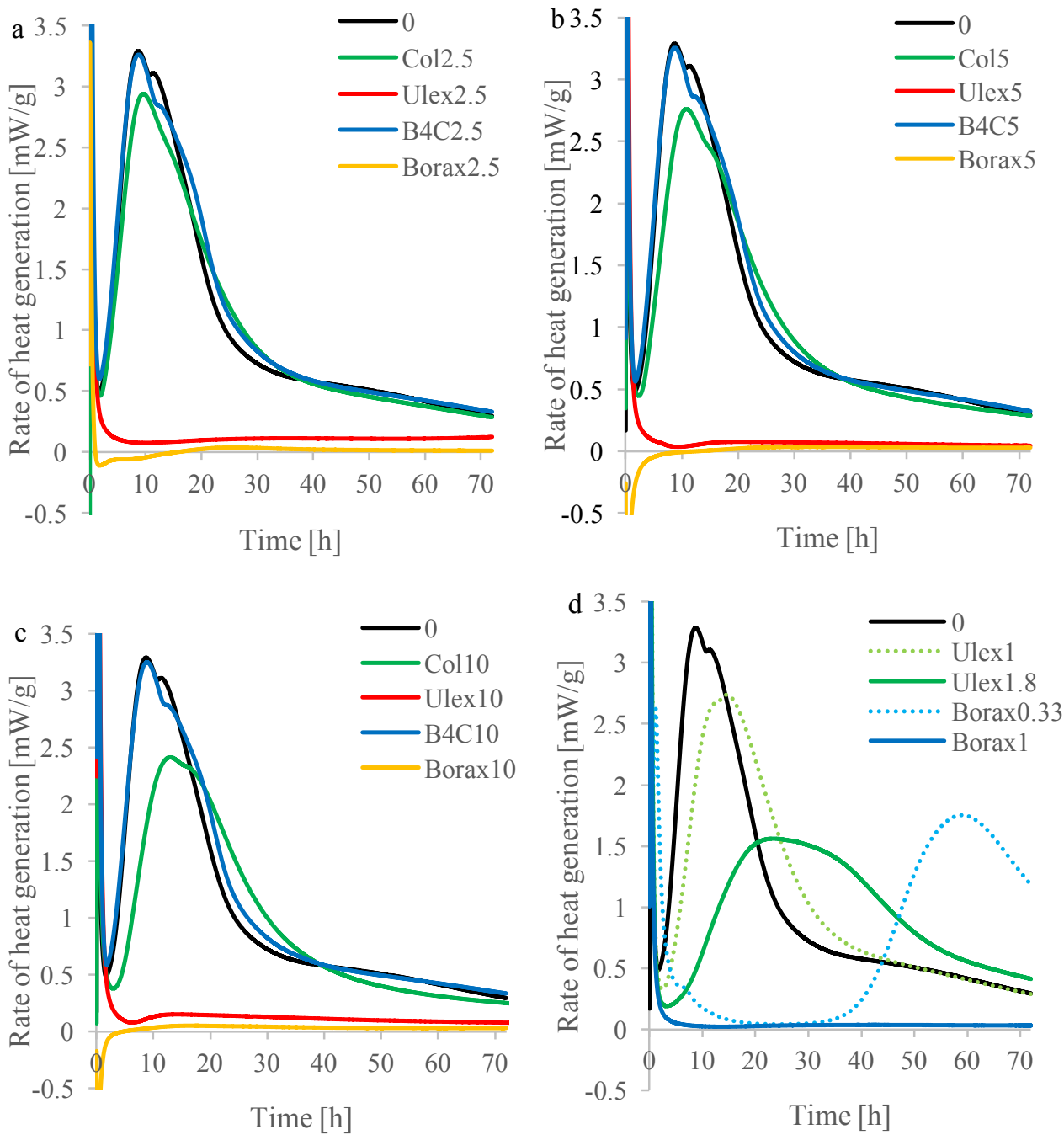

Fig. 2. The rate of heat generated per $1 \mathrm{~g}$ of cement during hydration of cement in mortar with different boron-containing aggregates (colemanite, ulexite, boron carbide, borax): (a) $2.5 \%$ (b) $5 \%$ (c) $10 \%$ of boron per cement mass, (d) 1 and $1.8 \%$ of boron per cement mass in the form of ulexite and 0.33 and $1 \%$ of boron in the form of borax, 0 - mortar without addition of boron-containing aggregate.

In the case of colemanite, it was noticed that along with the increase of aggregate content in the mortar, the maximum is lowered and the calorimetric curve shifts towards longer times. 
however, the hydration and hardening process with high boron content $(10 \%)$ is still quite good. Boron carbide is much better presented, whose calorimetric curve runs almost as in the reference mortar (without boron additives). Two more minerals: borax and ulexite, affect very negatively on the process of hydration. In graphs with boron contents from 2.5 to $10 \%$, the calorimetric curves are flat, mortars showed no setting. In the case of borax (above 5\% of B), heat is initially taken instead of being generated (endothermic process). Due to the strongly retarding effect of ulexite and borax, additionally tests were carried out with lower contents of these minerals, Fig. 2 d. Slight delay of the hydration process is observable at $1 \%$ $\mathrm{B}$ in the form of ulexite, $1.8 \% \mathrm{~B}$ causes stronger changes while the addition of $0.33 \% \mathrm{~B}$ in the form of borax causes a delay of the process to almost 40 hours.

Using calorimetric curves, the initial time of setting for particular mortars was determined. Two methods proposed by Ge et al. [11] and Bobrowicz [12] and presented in [13] were used. The first method is based on the first derivative of the function of the rate of heat generation in time (its maximum), the second method is based on the point of intersection of tangent to the minimum and tangent to the point of inflection. Results are presented on Fig. 3.

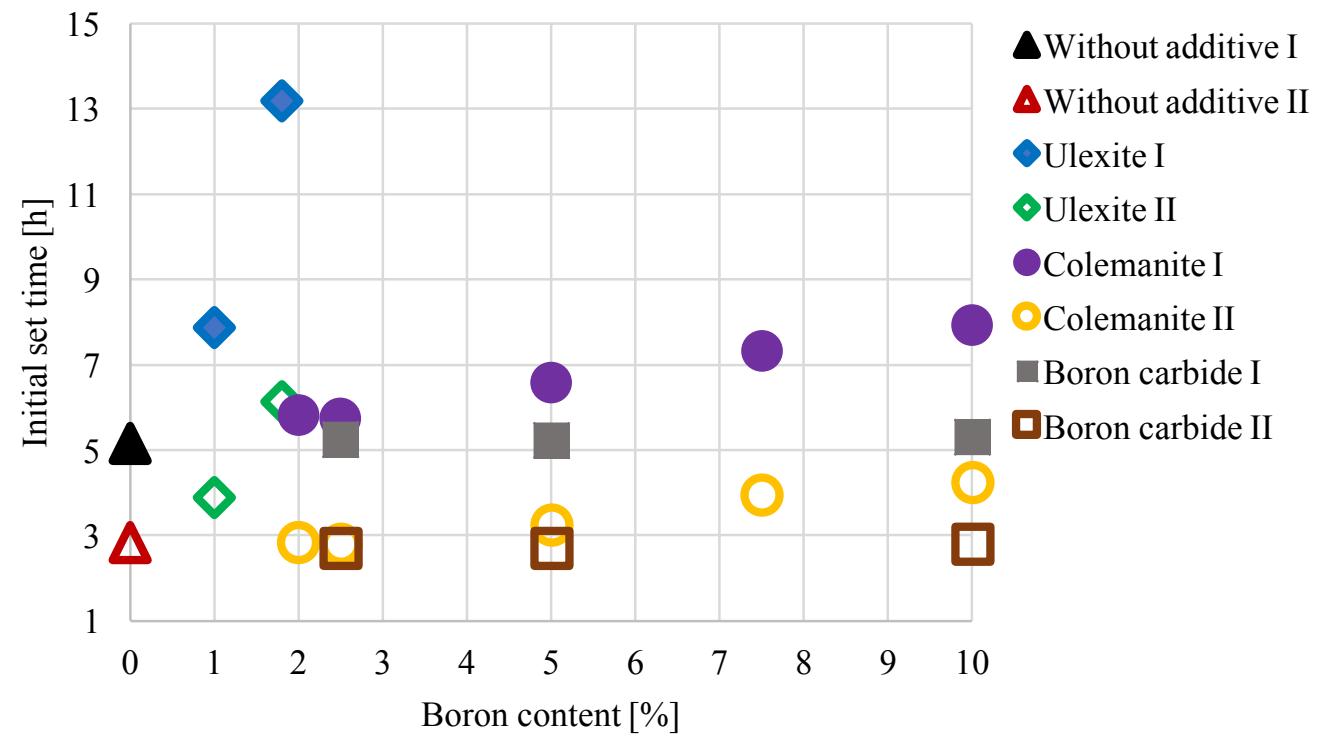

Fig. 3. Initial setting time determined by two methods: I (the first derivative) and II (intersection of tangents) as a \% of boron content in relation to cement mass in mortars.

The setting times determined by these two methods differ almost twice between each other. However, qualitatively the results are similar. The second method (intersection of tangents) seems to be more suitable for these materials, taking into account Vicat measurements of the initial setting time of the reference mortar which is $2.8 \mathrm{~h}$. Along with the increase of boron content in the mortar, the initial setting time rises. Only the addition of boron carbide does not change the initial setting time. With the addition of $0.33 \%$ of $\mathrm{B}$ in the form of borax, the initial setting time is $34.5 \mathrm{~h}$ by method I and $39 \mathrm{~h}$ by method II. To increase the readability of the results, in Fig. 4, the initial setting time of mortar with borax was intentionally omitted.

For the compressive strength tests, samples with the optimal boron content for each aggregate were selected (Ulex 1.8, Kol5, B4C10, Borax0.33). The best strengths after $72 \mathrm{~h}$ of hardening were found in boron carbide $(28.4 \pm 1.2 \mathrm{MPa})$ and colemanite $(20.8 \pm 0.2 \mathrm{MPa})$ 
samples compared to the reference mortar $(25.4 \pm 0.8 \mathrm{MPa})$. Due to the long delay of the initial setting time of mortar with ulexite $(10.3 \pm 0.6 \mathrm{MPa})$ and borax $(1.1 \pm 0.6 \mathrm{MPa})$, they had much lower strength. $72 \mathrm{~h}$ compressive strength constituted about $60 \%$ of 28 -day strength in the case of reference mortar, and mortars with boron carbide and colemanite. For mortars with ulexite and borax the increase was much bigger due to low early strength. Regardless of the aggregate used, the 28-day strength of mortars with boron-bearing additives was lower than the reference mortar.

In Fig. 4 the relationship between the heat of hydration measured by isothermal calorimetry and the compressive strength obtained from tests according to EN 196-1 is shown. There is a clear increase in compressive strength of mortar with the increase in generated heat. The points are arranged along a straight line, so it can be considered that the calorimetric measurements allow for predicting the early strength of mortar with fairly good accuracy.

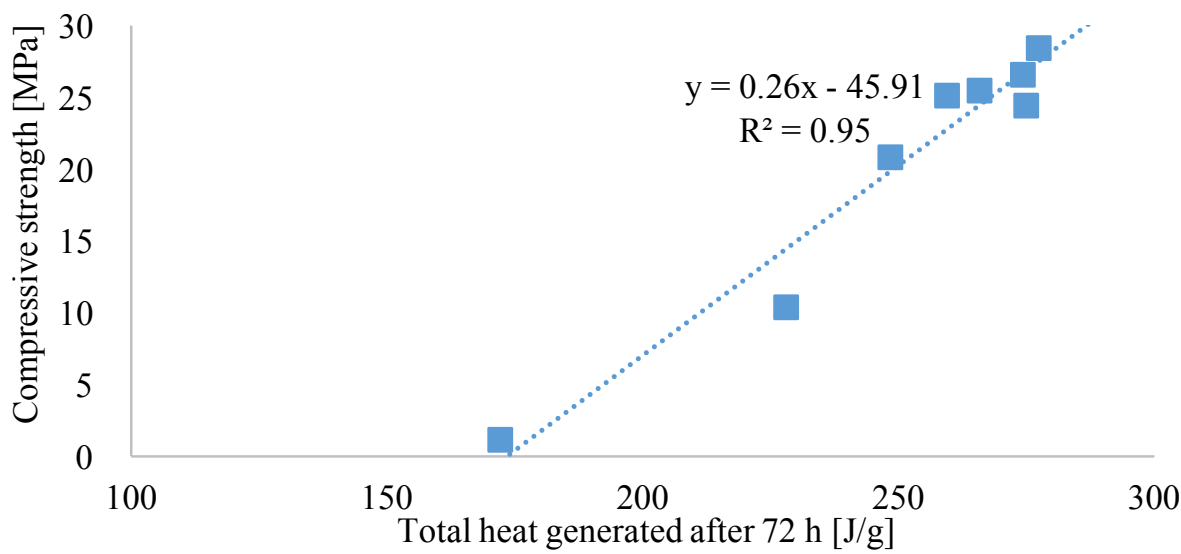

Fig. 4. Compressive strength of mortar with boron containing additives after $72 \mathrm{~h}$ of hardening as a function of hydration heat of cement released within 72 hours, determined on the basis of isothermal calorimetry.

The applicability of isothermal calorimetry for studying effects of boron-bearing aggregates in mortar has been confirmed. Considering numerous challenges associated with the design of concrete for radiation shielding structures [14] the method is supposed to be effectively supporting the selection of components of concrete to avoid its uncontrolled early hardening. This is needed to ensure the homogeneity of concrete not to weaken its radiation shielding capacity.

\section{Conclusions}

The investigation has shown that the addition of boron-containing aggregates into cement mortars significantly changes their functional properties.

The largest delaying effect on the initial setting time of cement had borax and ulexite, in greater quantities, they inhibited cement hydration process. Colemanite slightly delayed cement setting, while boron carbide did not cause any effects.

The linear relationship between heat generated after $72 \mathrm{~h}$ of hydration determined by isothermal calorimetry and compressive strength after $72 \mathrm{~h}$ of hardening was observed.

The isothermal calorimetry may be an appropriate tool for assessing the compatibility of aggregates with a cement matrix . 
The financial support from the National Centre for Research and Development in Poland is gratefully acknowledged (Project PBSII/A2/15/2014 "Durability and efficiency of concrete shields against ionizing radiation in nuclear power structures").

\section{References}

1. R.G. Jaeger, E.P. Blizard, A.B. Chilton, M. Grotenhuis, A. Hönig, T.A. Jaeger, H.H. Eisenlohr (Eds.), Engineering Compendium on Radiation Shielding, Volume 2: Shielding Materials (Springer-Verlag Berlin Heidelberg, 1975)

2. M.F. Kaplan, Concrete radiation shielding: nuclear physics, concrete properties, design and construction (Longman Scientific \& Technical, Harlow, England, 1989)

3. M. Mazgaj, T. Piotrowski, Brittle Matrix Composites 11, 361-370 (2015)

4. A.M. Brandt, D. Jóźwiak-Niedźwiedzka, Cement Wapno Beton 18, 1-22 (2013)

5. M.A. Glinicki, Longterm performance of concrete in shielding structures of nuclear power plants (in Polish) (IPPT PAN, Warszawa 2015)

6. M.H. Kharita, S. Yousef, M. Alnassar, Prog. Nucl. Energy. 53, 207-211 (2011)

7. L. Wadsö, C.P. Cooper-Jensen, P.M. Bentley, Phys. Rev. Accel. Beams. 20 1-8 (2017)

8. W. Kurdowski, Cement and Concrete Chemistry (Springer, 2014)

9. M. Gawlicki, W. Nocuń-Wczelik, Ł. Bąk, J. Therm. Anal. Calorim. 100, 571-576 (2010)

10. W. Nocuń-Wczelik, P. Czapik, Constr. Build. Mater. 38, 980-986 (2013)

11. Z. Ge, K. Wang, P.J. Sandberg, J.M. Ruiz, J. Adv. Concr. Technol. 7, 355-366 (2009)

12. J. Bobrowicz, Cement Wapno Beton 20, 401-410 (2015)

13. M.A. Glinicki, A. Antolik, M. Gawlicki, Constr. Build. Mater. 164, 731-738 (2018)

14. K. Kurtis, Y. Xi, M.A. Glinicki, J. Provis, E. Giannini, T. Fu, Concr. Int. 39, 29-35 (2017) 